\title{
MAQUIAVEL NA INGLATERRA: O LEITOR DAVID HUME
}

\author{
Machiavelli in England: David Hume the reader
}

\section{Nilo Henrique Neves dos Reis} UEFS

\begin{abstract}
Resumo: Os escritos de Nicolau Maquiavel foram lidos por várias pessoas de modo não confessional desde a sua divulgação. Indícios apontam que os ingleses tiveram acesso as suas obras já no reinado de Henrique VIII, ainda que de forma restrita à elite inglesa, que tinha familiaridade com o idioma italiano. Decerto que as obras do florentino ofereceram uma sólida contribuição ao pensamento político inglês, o que, por sua vez, estimulou uma reflexão crítica ao fenômeno político, bem como aos valores vigentes, pois, como se sabe, suas ideias serviram de inspiração para muitos escritores. A bem da verdade, cotejando as produções inglesas, principalmente após a guerra civil, sente-se a influência de Maquiavel. David Hume, que viveu entre 1711 a 1776, dois séculos depois da circulação dos escritos na Inglaterra, quando o florentino já era um referencial ali, não tinha como desconhecer as contribuições dos escritos políticos de Maquiavel, já que uma série de autores faziam referência diretas a ele, muitos dos quais, comentados pelo escocês. Em uma época em que era pernicioso fazer menções louváveis ao pensamento do florentino, há vestígios de que Hume usou estratégias para colocar suas posições próximas, e dado aos indícios encontrados neste escrito, defende-se a posição de que a familiaridade do escocês com os textos de Maquiavel era grande, visto que ele conhecia bem o "corpus machiavellicus".
\end{abstract}

Palavras-chave: Maquiavel. Hume. Familiaridade. Influência.

\begin{abstract}
Since their disclosures, Niccolò Machiavelli's writtens were read by lots of people in na nonconfessionally way. Evidence indicates that the Englishmen had access to his works already in the reign of Henry VIII, although in a restricted way to the English elite, who had familiarity with the Italian language. Certainly the works of the Florentine offered a solid contribution to English political thoughts, which stimulated a critical reflection on the political phenomenon as well as on the current values, for, as we know, his ideas served as inspiration for many writers. To be sure, comparing the English productions, especially after the civil war, Machiavelli's influence is well sensed. David Hume, who lived between 1711 and 1776, two centuries after the circulation of the writings in England, when the Florentine was already a referential there, one could not ignore the contributions of Machiavelli's political writings, since a series of authors made direct references to him, many of whom, commented by the Scotsman. At a time when it was pernicious to make commendable references to Florentine thoughts, there were traces that Hume used strategies to place his next positions, and given the clues found in this writing, the defended position is that the familiarity of the Scot with the texts of Machiavelli was considerable, since he knew the "corpus machiavellicus" well.
\end{abstract}

Keywords: Machiavelli. Hume. Familiarity. Influence.

\section{PARTE I - Maquiavel e suas obras na Inglaterra}

A influência de Nicolau Maquiavel e, nomeadamente, de suas obras políticas sobre a reflexão das coisas do Estado, são sentidas já nas suas primeiras edições. Concomitantemente às análises dos escritos, seguiu-se uma polêmica acerca das possíveis consequências de suas ideias que, aos da ordenação civil, mais tarde, foram tomadas como nefastas, motivo pelo qual seus livros deveriam ser combatidos, colocados como uma ameaça às relações religiosas, civis, sociais e políticas, o que, no 
decurso do tempo, criou uma atmosfera antimaquiaveliana no continente europeu, preocupando as autoridades.

De acordo com Salvatore Bongi, autor de Um Anneddoto di Bibliografia Machiavellesca ${ }^{1}$, devido a suas singularidades:

As obras machiavelescas, e especialmente o Príncipe, em graça das edições logo se multịplicaram, eram lidas com paixão; e na confusão moral e política na qual vivia a Itália até a metade do sécullo, não se imaginava dignamente os efeitos e os perigos da estampa, que enfim era uma instituição a qual podia se dizer-se nova. (...) A parte mais ingênua do povo amaldiçoava o escritor aos quais fundamentos maiores parecia que se reduziriam ao cullto da oportunidade, com a absoluta negação e com o desprezo das ideias morais e religiosas. (...) Por outro lado, os políticos não sabiam renuinciar ao estudo de um autor quie se distinguia entre tantos pela profundidade de observação e de pensamento, e que em qualquer lugar de seus escritos se mostrava amante da İtália, e a alentava com o fazê-la entrever no ainda vir tempos de glória e de prosperidade².

Como se nota em Bongi, os escritos do florentino ganharam contornos inusitados nas décadas seguintes à sula publicação, o que leva o comentador a denunciar o "acordo entre a Igreja e os governos, que cada coisa de Maquiavel fosse absolutamente

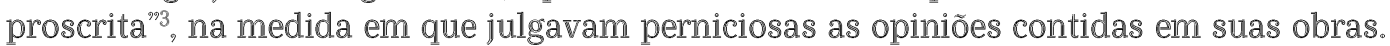
Assim, as ideias originadas em Florença logo se difundiram por toda Europa, bem como as medidas para sua não divulgação. Essa censura não impedia que outras edições aparecessem nos mercados, já que era comum aos impressores recorrerem à estratégia de utilizar "a data anterior à da primeira proibição papal". . Em conformidade com a exposição de Bongi, as obras de Maquiavel foram consideradas maléficas ao trono e ao altar, já que estavam resolutas em romper com o ordenamento civil e suas muitas páginas de análise ao fenômeno político. Em parte, o sucesso de Maquiavel mostra que seus leitores estavam justamente interessados na grande crítica ao domínio político; porém, outros viram como a questão da segurança do Estado era um tema fundamental em suas obras, principalmente em O Príncipe. Assim, o conhecimento exposto pelo florentino era conveniente para quem dominasse ou criticasse o poder.

À época da Guerra Civil, em 1640, Maquiavel era conhecido pelos ingleses, na medida em que:

é citado para mostrar que os governos populares são entre todos os outros, os menos ingratos, para alertar o povo contra o 'Cesarismo, para argumentar que (pelo menos em uma commonwealth) os homens, e não o dinheiro, são 'o Nervo da Guerra', e que a 'Prolongação da Magistratura é a Ruína do Governo popular'. Nestes e outros casos vemos o que vimos antes: uma visão republicana do Maquiavel republicano ${ }^{5}$.

Não obstante, se, por um lado, os Discursos sobre a primeira década de Tito Lívio (de agora em diante apenas Discorsi) de Maquiavel $^{6}$ serviam para reflexão dos críticos ao direito divino, por outro, O Príncipe inspirava aqueles que justificavam as prerrogativas monarquistas. Foi justamente isto que Felix Raab mostrou: que $^{7}$

\footnotetext{
${ }^{1}$ É o que se poderia chamar de "mapa de orientação"para o estudo de Adolph Gerber, exposto artigo: "All of five fictitious Italian Editions of writing of Machiavelli and three of those of Pietro Aretino printed by John Wolfe of London. (1584-1589)". II In: Modern Language Notes, Vol. 22, no 5 (May, 1907).

2 BONGI, S. "Un aneddoto di bibliografia Machiavellesca”. In: Archivo Storico Italiano, 5a Serie - XIX. Firenzi: G.P. Vieusseux, 1897, p. 127-129.

${ }^{3}$ Idem, p. 128.

${ }^{4}$ PUIGDOMENECH, Helena. Maquiavelo en España Madrid: Fundación Universitaria Española, 1988, p. 36

${ }^{5}$ RAAB, Felix. The English Face of Machiavelli A changing interpretation 1500 - 1700. London: Routledge, 2013, p. 188-189)

${ }^{6}$ MACHIAVELLI, Niccolò. Discursos sobre a primeira década de Tito Lívio. São Paulo: Martins Fontes, $2007 \mathrm{~b}$.

${ }^{7}$ RAAB, Felix. The English Face of Machiavelli. A changing interpretation $1500-1700$, op. cit.
} 
monarquistas e republicanos procuraram em Maquiavel as referências para sustentar suas perspectivas de mundo, afinal,

Maquiavel tornou-se mais relevante para os ingleses depois de 1640 . Convenientemente, a partir de 1642, novas facetas de Maquiavel começaram a ser vistas, à medida que a realidade objetiva da política inglesa aproximava-se do âmbito maquiavélico do poder político de facto. A característica mais importante desse desenvolvimento foi o súbito surgimento de uma compreensão de que Maquiavel fundamentadamente poderia ser considerado um crítico da ideia de regime único. No nível puramente político, Maquiavel parecia estar dizendo àqueles cujos ouvidos estavam devidamente sintonizados, que um úinico regime era uma coisa ruim. Esse argumento, como vimos, foi aplicado não apenas a Carlos I, mas também a Cromwell e Carlos $\bar{I}^{8}$.

A questão posta por Raab era, pois, ao mesmo tempo, a mais simples e a mais referencial: muitos usavam Maquiavel como referência em seus escritos. Além disso, fica latente nas entrelinhas que as obras do florentino circulavam na Inglaterra há décadas, o que permite pensar, por sua vez, que os escritores tivessem um imenso domínio de suas ideias. Este juízo talvez explique como cada autor o utiliza para justificar as próprias convicções. $\mathbb{E}$ as obras de Maquiavel realmente foram acolhidas no pensamento político inglês, permitindo transformações nas consciências humanas no modo de lidar com as coisas do Estado:

Esta mudança na política e no governo concomitante à nova inffluência exercida por Maquiavel depois da vitória do parlamento quando o Florentino assumiu uma influência maior como historiador republicano e político. Na verdade, a imagem antimaquiavélica de um Maquiavel pérfido continuava a desempenhar um papel significativo nos panfletos contra o rei e o Parlamento, e mais tarde contra o maquiavélico Cromwell. No entanto, na política e no governo, o Príncipe teve de ceder à nova razão do estado soberano, sendo ele monárquico ou parlamentar?

Isso abre mais perspectivas sobre a presença das obras de Maquiavel na Inglaterra, principalmente a respeito das leituras não confessionais do florentino. Contrariando, com certeza, a noção de que sua produção era considerada perniciosa.

Como se sabe, somente em $1640^{10}$, O Príncipe foi traduzido para o idioma inglês por Edward Dacres, o que deveria ser, por sua vez, o marco inicial da leitura das obras por parte dos britânicos. Não obstante, consta que, em $1560^{11}$, Peter Whitehorne havia traduzido um volume da Arte da guerra, o que mostra a circulação de outra obra do florentino em idioma vernáculo.

No panorama histórico das publicações de Maquiavel, há também a polêmica acerca da Testina $^{12}$, exemplares das obras de Maquiavel que teriam sido editados em 1550 - e envolvem, de certo modo, a circulação das mesmas pela Inglaterra, bem como outras edições que falam sobre o editor John Wolf. Suscitada pela primeira vez por

\footnotetext{
${ }^{8}$ Ibidem, p. 215.

${ }^{9}$ ARIENZO, Alessandro. "From Machiavellian Policy to Parliamentary reason of state: sketches in early Stuart political culture In Machiavellian Encounters" In: Tudor and Stuart England. Literary and Political influences from the Reformation to the Restoration Farnham: Ashgate, 2013, p. 155.

10 Na ediça de 1905, publicado por David Nutt, lê-se o I volume. The art of war, traduzido por Peter Whitehorne, em 1560; e The Prince, traduzido por Edward Dacres, em 1640. MACHIAVELLI, N. The Prince. London: Long Acre, 1905.

${ }^{11}$ Ibidem

12 O nome decorre da imagem de um busto do autor, na qual se mostra uma testa saliente. Nesta edição, as obras de Maquiavel estão divididas em cinco partes: Istorie fiorentine, Il Principe, a Vita de Castruccio Castracani e obras políticas menores; Discorsi sopra la prima deca di Tito Livio, L'Arte dela guerra, e, por último, L'Asino, Capitoli, Decennlai, La Mandragola e Clizia Esta edição data de 1550 e não há menção do local da impressão. Acerca da Testina, pode-se ler o texto de Massimo Firpo: Il volto, la Maschera, la caricatura. Sulla celebre 'testina' di Niccolò Machiavelli, "Rinascimento" 2012.
} 
Bartolomeo Gamba da Bassano ${ }^{13}$, a qual foi retomada por Bongi e depois serviu de estudo por Adolph Gerber. Este, conjuntamente com outros, concluiu que "a primeira edição da Testina, como suas quatro reimpressões"14, era resultante de traballho editorial do século XVII. É imprescindível recordar Charles Whibley, como bem observou J. H. Whitfield acerca das "trezentas referências ao Príncipe que Edward Meyer encontrou nos dramaturgos Elizabetanos"15, sem que houvesse uma tradução da obra anterior ao ano de 1640, o que causa certo embaraço, já que os ingleses estavam habituados à figura do "Old Nick", tão presente nas peças de Shakespeare. A despeito desta polêmica, Carlo Altini ${ }^{16}$ garante que

também sem considerar as traduções dos manuscritos do Príncipe e dos Discorsi conservados inéditos nas bibliotecas, nos anos quarenta e cinquenta do século XVI, existem inúmeras edições de obras publicadas de Maquiavel entre $1562 \mathrm{e}$ 1595: as principais traduções são da Arte da guerra (1562, editado por Peter Whitehorne) e História de Florença (1595, editado por Thomas Bedingfield) ${ }^{17}$.

Altini, depois desta assertiva, anuncia que obras do florentino eram confeccionadas na Inglaterra para atender "às elites inglesas" que desfrutavam o prazer de conhecer a língua italiana. Ademais, a grande virada das investigações ocorreria com Napolene Orsini, que, em estudo posterior às investigações de Gerber, mostra

que os elisabetanos não somente publicaram Maquiavel no original, mas também fizeram traduções de sua obra para o inglês, e que a tradução ainda é vigente. Não menos que cinco traduções MS do Príncipe, e três do Discourses, estão em posse de duas grandes bibliotecas inglesas, a do Bodleian e a do British Museum $^{18}$.

A existência destes manuscritos, como deixa claro Orsini ${ }^{19}$, coloca à parte o fato incontestável de que as obras do florentino circularam bem mais cedo do que a tradução oficial em 1640. É o que se poderia chamar de período de incorporação de ideias ou, ao menos, como marco introdutório, o que serve, igualmente, para conceber um retrato convencional de Maquiavel entre os ingleses.

Aliás, seria preciso acrescentar que Henrique VIII reinou na Inglaterra de 1509 até sua morte, em 1547. Auxiliado por muitos conselheiros, teve entre estes Thomas Cromwell, responsável direto por formular as medidas que baniram da Inglaterra a influência do bispo de Roma, dando ao monarca a supremacia também nos assuntos espirituais. Além disso, Cromwell foi o cumpridor na desapropriação das terras da Igreja Católica Romana, levando à morte todos aqueles que não fizeram o juramento de obediência religiosa ao novo chefe da Igreja Anglicana. Tendo em vista as ações do monarca inglês, Reginald Pole, cardeal inglês, escreveu:

Henrique VIII fez um mal à religião que nenhum apóstata ou herege havia tentado antes (...). Portanto, o que planejou Satanás como estratégia foi enviar ao rei de imediato um de seus conselheiros mais próximos, com as mais elaboradas

\footnotetext{
${ }^{13}$ DA GAMBA BASSANO, Bartolomeo. Serie dei testi di lingua. $E$ di altre opere importanti nella italiana letteratura scritte dal secolo XIV al XIX. Venezia: Arnaldo Forni, MDCCC XXXIX (1839).

${ }^{14}$ TARANTINO, Maurizio. "Testina" In: Machiavelli. Enciclopedia Machiavelliana (a cura di Gennaro Sasso). Roma: Treccani, vi. II, pp. 609-610, 2014, p. 609.

${ }^{15}$ WHITFIELD, J.H. The Charlecote Manuscript of Machiavelli's "Prince". (Reprinted from Italian Studies, Vol. XXII, 1967), p. 6 .

${ }^{16}$ ALTINI, Carlo. "Inghilterra" In: Machiavelli. Enciclopedia Machiavelliana, (a cura di Gennaro Sasso). Roma: Treccani, v. II, 2014, p. 20

17 Ibidem, p. 20.

${ }^{18}$ ORSINI, Napoleone. "Elizabethan manuscript translation of Machiavelli's Prince". In: Joumal of the Warburg Institute, vol. 1, no 2 (Oct. 1937), p. 166.

${ }^{19}$ Convem também consultar ORSINI, Napoleone. Studii sul Rinascimento Italiano in Inghilterra. Con alcuni testi inglesi inediti. Firenzi: G. C. Sansoni, $1937 \mathrm{~b}$.
} 
ordens, para que seguisse de perto o monarca e lhe dissesse todas as coisas que fossem agradáveis aos seus desejos e paixões, os quais possuíam em seu grau máximo, para que finalmente concordasse com tudo o que lhe fosse proferido. Tinham tanta força suas palavras que, ao ouvi-las, facillmente foi perceptível que o rei se havia deixado aprisionar e que não reclamaria por isso, senão que aceitaria tudo de bom grado (...). Deste modo, então, se quer saber seu nome, o chamam Cromwell (... $)^{20}$.

Esta foi a primeira análise de Pole sobre a concupiscência de Henrique VIII. Não obstante, o que merece um exame mais detalhado seria saber qual foi a fonte causadora dessa atração repentina do rei em buscar certos prazeres, bem como entender como a cobiça foi colocada em seu coração, a ponto de promover ações que rompessem com a unidade da fé entre Inglaterra e Roma. Nesse sentido, torna-se interessante o relato de Pole sobre seu diálogo com Thomas Cromwell, ocorrido na residência do Cardeal Wolsey, no qual afirma que:

Discutimos sobre muitas coisas (...) mas, quando viu que eu quase não tinha sido convencido por seu discurso, e sim que o reprovava, coisa que para ele não foi nada diffícil deduzir a partir do meu rosto e de minhas palavias (...). Ele tinha uim livro escrito por um homem moderno (...). Encontrei que este livro era de tal forma que parecia escrito por um inimigo da espécie humana e, que nele, todos os planos do inimigo são detalhados, semelhante aos métodos pelos quais a religião, a piedade e qualquer tipo de virtude podem ser destruídos (...). Quando comecei a lê-lo, percebi que estava escrito pelo dedo de Satanás (...). Nunca hesitarei em falar que está escrito pelos dedos de Satanás, por mais que seu autor se apresente como um homem. Para que não fique mais perplexo, este livro foi escrito sob o nome de Maquiavel, uim florentino totalmente indigno de ter como pátria uma cidade tão nobre ${ }^{21}$.

Segundo Lefort, e como se observou acima, Cromwell havia sugerido que Pole lesse $O$ Príncipe ${ }^{22}$, o que, segundo o cardeal, foi a ocasião para perceber o quanto da influência diabólica se presentificava naquelas palavras. Graças a esta interpretação, talvez seja profícuo lembrar que Pole, em sua residência em Pádua, reunia-se com vários leitores que conheciam "as obras do autor do Príncipe"23. Convém ressaltar que Pole morreu em 1558; porém, durante sua vida, foi responsável por duas atitudes. Primeiro, em sua obra Defense of the Unity of the Church ${ }^{24}$, também conhecida como De Unitate, ele tentou reconstruir um caminho que reaproximasse Henrique VIII e a Igreja de Roma: e, em um segundo escrito, Apologia Ad Carolum Quintum Caesarem², através do qual foi o consciencioso propagandista contra a obra do florentino, pois julgava o seu conteúdo pernicioso à fé cristã. Vittorio Frajese diz que Ambrogio Catarino, em sua "Ennationes (1552), chamou Maquiavel de "ímpio e ateu"26. E Lefort acrescenta que este mesmo dominicano tendo lido os Discorsi, tenha sugerido que os pusesse "entre os livros que os cristãos devem odiar"27. Não obstante, talvez o maior desafeto que a obra do florentino conquistou foi com o cardeal Giovanni Pietro Carafa. Este, segundo Puigdomènech ${ }^{28}$, tentou dissuadir Clemente VII, durante seu pontificado, a proibir a circulação de livros perniciosos aos ensinamentos cristãos. Sem sucesso. Porém, à medida que se tornou o

${ }^{20}$ POLE, Cardenal. "Apología Ad Carolum Quintum Caesarem”. In: El Cardenal Pole de la política como virtud en tiempos de El Príncipe Madrid: Unión Editoriall, 2013, p. 93-122.

${ }^{21}$ Ibidem, p. 93-122.

${ }^{22}$ LEFORT, Claud. Maquiavelo: Lecturas de lo político. Fernández: Trotta, 2010, p. 19.

${ }^{23}$ COLI, Daniela. Hobbes, Roma e Machiavelli nell'Inghilterra degli Stuarts. Firenze: Casa Editrice le Lettere, 2009, p. 110-111.

${ }^{24}$ POLE, Cardenal. Defense of the Unity of the Church Westminster, Mariland: The Newman, 1965.

${ }^{25}$ POLE, Apologia Ad Carolum Quintum Caesarem, op.cit.

${ }^{26}$ FRAJESE, Vittorio. "Index librorum prohibitorum". In: Machiavelli. Enciclopedia Machiavelliana (a cura di Gennaro Sasso). Roma: Treccani, v. II, 2014, p. 12.

${ }^{27}$ LEFORT, Claud. Maquiavelo: Lecturas de lo político, o. cit., p. 19.

${ }^{28}$ PUIGDOMENECH, Helena. Maquiavelo en España, op. cit., p. 30. 
Papa Paulo IV, dedicou-se a uma regeneração da moral, criando o primeiro Índice de livros proibidos pela Igreja Católica, o Index Librorum Prohibitorum ${ }^{29}$, que coloca em sua lista o nome de Maquiavel.

É indispensável notar que o Index foi criado em 1559, porém, a obra de Maquiavel já era conhecida por seus detratores católicos há tempos. As embarcações que comercializavam com os ingleses estavam destinadas não só a transportar mercadorias, como também ideias. $\mathrm{E}$, consoante Baron, foi na "década de 1520-1530, durante a última parte do reinado de Henrique VIII, que as ideias renascentistas sobre história e política, problemas sociais e comportamento humano, chegaram à Inglaterra em uma corrente ininterrupta"30, corroborando a proposição de que obras italianas circulavam com frequência em solo britânico.

Ademais, é preciso pontuar, como observara Frances A. Yates, em 1937, em Italian Teachers in Elizabeth England, que "aprender novas línguas era mais essencial para o isabelino do que para o inglês moderno, pelo simples fato de que naquela época a língua inglesa era uma língua falada apenas na Inglaterra"31, o que sugere que "o italiano foi muito vigorosamente ensinado e aprendido na Inglaterra no período elisabetano" 32 , a tal ponto que foi comprovado que "Elizabete I falava o italiano e possuía a cópia da Expulsão da Besta Triunfante de Giordano Bruno"33. Se esta indicação é correta, não causa surpresa que a proposição de que

Nos seiscentos, na Grã-Bretanha, a influência de Maquiavel foi tão profunda que os ingleses chegaram a crer - como se afirma nas célebres "BriefLives" - de deverem a imortalidade quase exclusivamente à fama pelas ações realizadas durante a vida. São os Discursos sobre a primeira década de Tito Lívio que suscitam nos ingleses seja a admiração pelas antiguidades romanas, o desejo de monumentos e de escritos por serem recordados pelos posteriores, seja o interesse pela história de Roma. Foi, sobretudo, pelos Discursos, mais que pelo Príncipe, que Maquiavel foi conhecido na Inglaterra do período Tudor através da obra de William Thomas ${ }^{34}$.

Esta passagem apenas confirma a ideia de que Maquiavel era conhecido bem antes de sua tradução em 1640. Mario Praz, já havia posto que Francis Bacon era "leitor atento de Maquiavel" quando ele agradece a "Maquiavel e a outros que escrevem sobre o que os homens fazem, e o que não deveriam fazer"35. Além disso, em outro escrito, Praz ${ }^{36}$ discorre que Cromwell, dentre os primeiros homens de Estado, usava a obra do Florentino "sem confessar" sula consulta, confirmando as passagens de Pole, bem como de Lefort. Do mesmo modo, Praz aponta Walter Raleigh como leitor do florentino. É imprescindível notar que se trata de personalidades que transitaram na corte inglesa, que, segundo parece, tinham o hábito de ler Maquiavel sem confessar essa conduta.

De tudo exposto, não resta dúvida de que a presença das obras de Maquiavel na Inglaterra era uma realidade e que, em conformidade com Raab ${ }^{37}$ e Pocock ${ }^{38}$, os escritos

${ }^{29}$ Acerca desta questão vale consultar Vittorio Frajese: Nascita dellindice. La censura ecclesiastica dal Rinascimento ala Controriforma. Brescia, 2008.

${ }^{30}$ BARON, Hans. En busca del humanismo cívico florentino: ensayos sobre el cambio del pensamiento medieval al moderno. México: Fondo de Cultura Económica, 1993, p. 256.

${ }^{31}$ YATES, Frances A. "Italian Teachers in Elizabeth England". In: Journal of the Warburg Institute, V. 1, no 2 (Oct., 1937) p. 103

${ }^{32}$ Ibidem, p. 115.

${ }^{33}$ CILIBERTO, Michele. "Machiavelli e Il Principe nell'Tnghilterra tra il XVI e il XVII secolo". In: Il Principe di Niccolo Machiavelli e il suo tempo. 1513 - 2013. Roma: Treccani, 2013, p. 236.

${ }^{34}$ COLI, Daniela. Hobbes, Roma e Machiavelli nell'Tnghilterra degli Stuarts, op. cit., p. 111.

${ }^{35}$ PRAZ, Mario. "The flaming heart: essays on Crashaw, Machiavelli, and other studies". In: the relations between Italian and English literature from Chaucer to T.S. Eliot by Mario Praz. New York: The Norton, 1973, p. 100-101.

${ }^{36}$ PRAZ, Mario. Machiavelli in Inghilterra ed altri saggi. Firenzi: Tumminelli, 1943, p. 149

${ }^{37} \mathrm{RAAB}$, Felix. The English Face of Machiavelli, op. cit.

${ }^{38}$ POCOCK, J.G.A. The machiavellian moment. Florentine political thought and the Atlantic Republican tradition. New Jersey: Princeton, 2003. 
do florentino passaram a dominar uma parte do debate público, apesar das providências aconselhadas pela Igreja Católica e dos reinos. Acrescente-se que, além das conversões religiosas que estavam acontecendo na Europa, bem como a desconfiança atribuída pelo altar ao termo "maquiaveliano", uma forma de pensar a política estava simplesmente

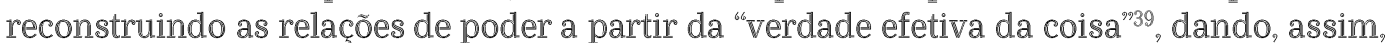
mais autonomia à política, separando-a das febres éticas do político, à medida que o poder tem como o fim em si mesmo.

John Pocock ${ }^{40}$, em The Machiavellian moment, mostrou que havia um ambiente maquiaveliano que inspirava os autores ingleses, à proporção que aumenta o número de leitores sensíveis aos comentários do florentino, principalmente entre os que têm perspicácia de espírito. No entanto, o que não parece claro na produção filosófica de David Hume é que não tenha recorrido ao auxílio do florentino já na sua obra magna de 1738, o Tratado da natureza humana. Além disso, como foi um ensaísta crítico da política, sendo inclusive autor de uma História da Inglaterra, que esmiúça com traços de realismo político os problemas desta nação ao longo dos séculos, (isto é, de sua origem ao ano de 1688) não se imiscuísse com um teórico político que analisa este fenômeno a partir dos conflitos e interesses dos homens, visando a boa ordenação.

Hume escreveu uma História da Inglaterra que segue "da invasão de Júlio César à Revolução de $1688^{\prime \prime}$ - este é o subtítulo de seu escrito -, o que permitiria perceber a contribuição das obras do florentino para justificar a queda dos Stuarts, bem como as críticas feita a Oliver Cromwell. Hume conhece o interior da trama lhistórica inglesa, e devido à sua agudeza de espírito, limita às sucessivas interpretações por uma perspectiva do realismo político sem mencionar as obras maquiavelianas. Talvez, ele se insira no rol dos leitores não confessionais do florentino, entre os que não desejam ser taxados de infiéis socialmente. Talvez, o escocês tenha lido Maquiavel, porém, julgou indispensável adotar estratégias como a omissão. Outros autores, audaciosos, como Francis Bacon e James Harrington aceitaram o florentino como referencial para suas próprias produções. Além disso, "o divino Maquiavel", como lembra Altini, em estreita relação com Henry Neville, foi tomado "como o maior expoente do republicanismo por Francis Osborne, para Marchamont Nedham, Henry Neville, Algernon Sidney, John Trenchard, Walter Moyle, Thomas Gordon, Richard Price e Joseph Priestley ${ }^{\text {m41 }}$, o que contribuiria ainda mais para acentuar a presença do florentino entre os ingleses, já que estes o louvaram em seus escritos, o que teria promovido a leitura de Maquiavel por parte do historiador Hume. Na verdade, à época de Hume, o vocábulo "Maquiavel" estava envenenado por uma série de motivos políticos e religiosos, o que era extremamente prejudicial às carreiras públicas, embaraçando pretensões pessoais por parte das autoridades da Igreja. $\mathbb{E}$, examinando a produção acadêmica do escocês, bem como sua atitude de enviar um escrito a um Henry Home com a seguinte ressalva: "Eu te imploro que não a reveles a ninguém, exceto ao Sr. Hamilton, caso ele tenha vontade; e deixe me saber ao seu prazer se a recebeu, a leu, e a queimou. Eu nem mesmo faço um uso anônimo dela, o que não seria impróprio, por temer acidentes ${ }^{n+42}$. A partir desta confissão, começa-se a conceber um perfil psicológico para Hume, evidenciando a sua preocupação com a reprovação e/ou os efeitos colaterais das interpretações de suas ideias. Surpreendente, portanto, que mesmo escrevendo de forma reticente, o filósofo imaginasse que sua primeira publicação ganhasse imediato prestígio.

\section{PARTE II - O leitor David Hume}

\footnotetext{
${ }^{39}$ MAQUIAVEL, Nicollau. O Príncipe Edição bilíngue. São Paulo: Hedra, 2007a, p. 153.

${ }^{40}$ POCOCK, J.G.A. The machiavellian moment Florentine political thought and the Atlantic Republican tradition, op.cit.

${ }^{41}$ ALTINI, Carlo. "Inghilterra" In Machiavelli Enciclopedia Machiavelliana, op.cit., p. 21.

${ }^{42}$ KLIBANSKY, Raymond, MOSSNER, Ernest C. New letters of David Hume. Oxford: At the Clarendon Press, 1969, p. 2 .
} 
Com a morte de Cromwell e a imperícia de seu filho Richard em lidar com a política, o exército não tardou a entrar em conflito por conta dos interesses de seus comandantes. Depois de uma série de acordos, ficou decidido pela 'restauração' da Monarquia, na figura do monarca Carlos II que, doravante, reinaria por uma concessão do Parlamento, o que ficou definitivamente claro com a Revolução de 1688. A partir desta data, a Inglaterra teria um rei que reinava, mas seria governada por políticos que dominassem as votações do Parlamento. E, assim, foi a política partidária entre "whigs" e "tories" doravante, marcada pelo conflito do domínio político, embora os primeiros tivessem mantido a proeminência de 1714 a 1783 .

As lutas partidárias não são acidentais, elas são disputas complexas que envolvem, ao final, a dominação do cenário político. E como disse um analista deste fenômeno: "os fins da política são tantos quantas forem as metas a que um grupo organizado se propõe, segundo os tempos e as circunstâncias" ${ }^{\text {"13 }}$, razão pela qual a luta entre os aludidos partidos visava ao controle do Estado. Afinal de contas, através deste mecanismo, ocorria a "dominação do homem sobre o homem, fundada no instrumento da violência legítima" ${ }^{\prime \prime 4}$. Bem entendido, a violência é somente mais um recurso, entre tantos, para o exercício da dominação, usada "apenas em casos extremos, para impedir a insubordinação e a desobediência dos submetidos" ${ }^{\prime \prime 4}$, pois a dominação tem como base o controle das coisas que são socialmente valorizados, seja no plano material, seja no nível simbólico.

A censura é outro elemento fundamental para dominação, na medida em que legitima os textos canônicos e, ao mesmo tempo, classifica os intrusos que devem ser banidos ou não serem considerados socialmente relevantes. Graças às censuras, às vezes o autor expõe seu escrito de modo que lido como está não possa ser entendido pelo leitor desatento. No entanto, para que seja compreendido o que ele realmente queria transmitir, o leitor precisa ligar as partes, percorrer os contomos, entender o que não pode ser dito abertamente, senão perceber por debaixo de sua estratégia. Este acordo, que foi bem observado por Heather Arden e transcrito no capítulo "o filósofo e a censura", de João Paulo Monteiro, diz que "os filósofos do século XVIII estavam sempre à procura de novos meios de expressão que lhes permitissem publicar o que era inaceitável para as autoridades políticas e eclesiásticas"46. Ao tempo em que Monteiro elege esta passagem, neste escrito, ele oferece uma visão de como se deve ver as obras de Hume. Evidentemente que ele foca nos escritos religiosos do escocês, porém, bem entendido, esta censura alcançava proporções consideráveis, motivo pelo qual ele relembra a posição de Flew acerca da escrita do filósofo:

para evitar acusações de uma gravidade que na época nada tinha de desprezível, Hume envolve o seu discurso em múltiplos véus de discrição, recorrendo a formas indirectas e obliquas de expressão e a efeitos de mascaramentos, utilizando toda uma complexa estratégia, cheia de manobras defensivas ${ }^{47}$.

Em estreita sintonia com Flew, o que Monteiro chama atenção para os escritos religiosos de Hume serve como orientação para a sua leitura do Tratado da natureza humana. O escocês tinha uma inquietação filosófica quanto à boa interpretação de suas obras, bem como receio de que suas posições políticas e religiosas fossem indevidamente tomadas como nocivas. Em uma época em que o entusiasmo de uns (whigs) e a superstição de outros (tories) era tomado com zelo extremo, e o facciosismo acrítico promovia uma intolerância anteposições distintas, Hume não hesitou em rever

\footnotetext{
${ }^{43}$ BOBBIO, Norberto. Teoria geral da política: a filosofia política e as lições dos clássicos. Rio de Janeiro: Elsevier, 2000, p. 167.

${ }^{44}$ WEBER, Max. A política como vocação. São Paulo: Cultrix, 2004, p. 57.

${ }^{45}$ BOBBIO, Norberto. Teoria geral da política a filosofia política e as lições dos clássicos, op. cit., p. 163.

${ }^{46}$ MONTETRO, João Paulo. Hume e a epistemologia. Vila da Maia: Imprensa Nacional/Casa da Moeda, 1984, $\mathrm{p}$. 167.

${ }_{47}^{17}$ Ibidem, p. 166.
} 
simultaneamente sua obra, cortando partes, reescrevendo outras a fim de que sua obra tivesse um julgamento mais justo. Esta situação fica mais clara na sua autobiografia, pois ali, mostra o que aconteceu com a publicação de sua primeira obra. Ele diz: "jamais uma tentativa literária foi mais infeliz do que meu Tratado da Natureza Humana. Ele nasceu morto da gráfica, sem alcançar qualquer distinção, sem despertar sequer um murmúrio entre os zelotes" ${ }^{\prime \prime 4}$. O livro era uma obra singullar na filosofia, como a posterioridade comprovará, mas, ao seu tempo, não há dúvida que desagradou pessoas influentes que obstaculizaram sua intenção de ser professor de filosofia na Universidade de Edimburgo. E Hume confessa bem mais tarde como o facciosismo era animado por uma posição exclusiva, quando se refere à sua História da Inglaterra, especialmente na parte que trata da ascensão dos Stuart ao poder, pois sua

Decepção foi miserável: voltaram-se contra mim críticas, reprovações de todo tipo e mesmo manifestação de ódio; ingleses, escoceses e irlandeses; Whigs e Tories, membro do clero e do parlamento, livres pensadores e religiosos, patriotas e cortesãos uniram-se na sua raiva contra o homem que tivera a pretensão de derramar uma lágrima generosa pelo destino de Carlos I e pelo Conde de Strafford ${ }^{49}$.

Esta passagem de Hume é um sinal de que certas questões políticas do pretérito ainda repercutiam em seu presente, o que, de certo modo, permite pensar como "o pernicioso Maquiavel" e seus admiradores podiam ser prejudicados. De fato, o "legado do humanismo cívico, tal como foi transmitido por Maquiavel e seus sucessores ${ }^{\prime \prime 50}$ estava vivo no século XVIII. Todavia, se os livros do florentino tinham uma ênfase no fenômeno das ações dos homens públicos, gerando uma consciência crítica das circunstâncias políticas, acima de tudo serviam para mostrar como funcionavam os bastidores do poder, o que levaria os ollhos dos leitores para os fatos que ocorrem em segredo, desvelando como a corrupção - instrumento bastante usado pelo governo inglês - era uma espécie de óleo para o funcionamento da máquina estatal, dando-lhes sinais de como a política estava ligada à natureza humana e como as paixões são sabiamente interesseiras, podendo modificar a conduta dos homens. Se, por um lado, a história sob o crivo do florentino havia ensinado o quanto a corrupção (quando uma república se torna "corrompidíssima") era perniciosa para o Estado, por outro, Hume assistiu Robert Walpole, ministro entre 1721 e 1742 , manejar esta ferramenta com perícia magistral, tornando-se uma espécie de modelo no uso eficiente do favorecimento de uns, sinecuras para outros, o que permitiu, na leitura de um historiador do século XX, aos "whigs pastarem e engordarem e, à falta de qualquer oposição genuína" ${ }^{n ! 51}$, dominarem o cenário político por cinco décadas, "constantemente se aliando ou se separando, sob ordens ora deste ora daquele distribuidor de benesses"52. Ao que parece, Walpole soube lidar com este instrumento.

A compreensão da corrupção estava associada à ideia de degeneração, de declínio das coisas e se liga à questão moral, o que, por sua vez, era um valor socialmente condenável à proporção que, crescendo a corrupção, frustrava as expectativas dos cidadãos e comprometia seu comportamento social, sendo altamente prejudicial à boa ordenação social do Estado, uma vez que coloca os interesses próprios dos políticos à frente dos coletivos. Não obstante a ideia prejudicial da corrupção, Walpole tỉnha um senso político pragmático, pois, criou as condições favoráveis para o desenvolvimento do comércio, evitando guerras externas e diminuiu o peso dos impostos dos industriais e comerciantes. Para facilitar sua administração, conseguiu a maioria parlamentar com a

${ }^{48}$ HUME, David. Ensaios morais, políticos eliterários. Rio de Janeiro: Topbooks, 2004, p. 74.

${ }^{49}$ Tbidem, 2004, p. 77.

${ }^{50}$ POCOCK, J.G.A. The machiavellian moment. Florentine political thought and the Atlantic Republican tradition, op. cit., p. 113.

${ }^{51}$ MORTON, A.L. A história do poṽo inglês. Rio de Janeiro: Civilização Brasileira, 1970, p. 264.

52 Ibidem, p. 264. 
ambição dos homens. E Hume percebeu virtudes e vícios em Walpole, vendo na ferramenta da corrupção uma atividade específica da política, pois, de acordo com o escocês, durante "sula gestão, o comércio floresceu, a liberdade declinou e a educação ficou arruinada" 53 , mostrando que este ministro usava bem o domínio político, fazendo uso eficiente do poder, recorrendo à corrupção como uma ferramenta de persuasão na defesa de seus interesses políticos. Hume, semelhante a Maquiavel, não lida com a corrupção como uma questão moral, mas como política. Para ambos, quando institucionalizada no regime político leva à ruína do Estado. Não obstante, o florentino observou "com que facilidade os homens se corrompem e se tomam de natureza contrária (...), enceguecidos por um pouco de ambição" most, mostrando como os homens deixam de seguir os bons costumes para seguir os maus. E Robert Walpole não era um moralista, mas sim um ator político que dominou o cenário político por vinte anos, em meio à presença perniciosa das facções, sustentando-se como principal ministro, fazendo bom uso das lutas intestinas entre os dois partidos para ficar à frente do poder.

o facciosismo em si, por seu caráter subversivo, era um obstáculo real à boa ordenação civil, seja nas cidades-estados italianas ou na Grã-Bretanlha. Talvez, por isto, este tema estivesse tão presente nas reflexões destes dois filósofos. A Hume, como sucessor no tempo, tinha ainda a possibilidade de consultar as considerações do florentino, entender como ocorreu no passado este fenômeno para enriquecer suas análises, permitindo-o reconstruir uma perspectiva mais densa do assunto, recolhendo as contribuições pretéritas e que lhe permitisse edificar uma percepção política mais adequada às circunstâncias concretas da Inglaterra de sua era. Hume compartillha de uma posição próxima do realismo político, motivo pelo qual busca no conhecimento histórico o saber para bem ordenar a sociedade. E Hume compartilha a ideia de que "o homem que só é suscetível à amizade, sem espírito público ou preocupação com a comunidade, é deficiente na parte mais concreta da virtude" ${ }^{n 5}$, e é, portanto, um ser visceralmente indiferente ao bem-estar dos demais, prejudicial à sociedade civil. Ocorre que, na Inglaterra da época de Hume, segundo ele, "dos dois lados há fanáticos suficientes, que inflamam as paixões de seus partidários e, a pretexto de defenderem o bem público, só visam aos interesses e objetivos da facção a que pertencem" (HUME, 2004, 122). Enquanto defensor de uma atitude moderadora, Hume tem, antes de mais nada, boas razões para consultar as posições de Maquiavel acerca das facções. Ademais, como compartillhava a interpretação de que em política o conflito é inevitável entre os homens, a vida deles será marcada por uma luta ininterrupta; o que leva o ator político, por uma razão de Estado, utilizar os meios necessários para garantir a ordenação civil, ainda que estes instrumentos políticos sejam contrários aos preceitos da moral.

Assim, com uma perspectiva semelhante aos problemas enfrentados por Hume, vê-se que essa visão realista da política estava presente nas obras de Maquiavel. Se o escocês tivesse lido o florentino, decerto que seria sensível aos seus raciocínios, o que levaria a uma conformidade de resultados próximos. Não obstante, Hume não gostaria de ser associado a Maquiavel, o que levaria a sofrer preconceitos de ser infiel, ímpio e ateu, contrário aos valores transmitidos pela tradição, autor de obras perniciosas. No entanto, se Hume era um leitor não confessional do florentino, ele poderia recorrer a artifícios na exposição de temas maquiavelianos contra as formas de críticas por uma associação direta ao pernicioso escritor florentino. Através dessa técnica, Hume continuava ligado estreitamente às ideias de Maquiavel sem que renunciasse às suas reflexões, que sempre foram incalculáveis aos teóricos da política. Não se deve desconsiderar que nos anos em que a leitura do florentino foi tolerada, isto se deu com raras exceções, pois, "mesmo aqueles que leram com interesse as obras de Maquiavel, adotando os princípios morais e políticos, foram forçados em público para mostrar desprendimento, se não desprezo, no que se refere às lições 'escandalosas' de

${ }^{53}$ HUME, David. Ensaios morais, políticos eliterários, op. citu, p. 797.

${ }^{54}$ MAQUIAVEL, Nicolau. Discursos sobre a primeira década de Tito Lívio, op.cit. I, 42, p.131.

${ }^{55}$ HUME, David. Ensalos morais, políticos eliterários, op.cit., 122. 
Maquiavel ${ }^{n 56}$. Em uma nação em que política e economia estavam vinculadas à religião, a leitura do florentino era condenável, principalmente porque o Evangelho exprimia a conduta socialmente reverenciadla, conforme assinalou Altini.

Graças à noção perniciosa associada às obras do florentino e também à presença da força religiosa na Inglaterra, Maquiavel foi transformado na "personificação do mal e de todos os vícios humanos" ${ }^{257}$, bem como quando se toma em consideração que os escritos religiosos de Hume tinham "um caráter altamente problemático. (...) E essa situação problemática é por ele sentida logo desde a sua primeira obra, o Tratado da Natureza Humana"58. É fácil conceber que Hume não deseja se vincular à figura de Maquiavel, dado aos receios de que não seja bem compreendido ( - na carta a Henry Home, já aludida, ele escreve:

estou castrando minha obra, ou seja, eliminando suas partes nobres, me empenhando para cometer o mínimo de infiração possível; antes que não possa mais fazer de conta em colocá-la nas mãos do doutor. Isso é pouco covarde de minha parte, pelo qual me cuilpo; ainda que eu acredite que nenhuim dos meus amigos me culparás

Assim, em face da passagem acima, poder-se-ia dizer que a escrita de Hume se enquadra na respectiva psicologia dita por Flew e Monteiro, ainda que se queira dizer prudente para seu tempo.

A hipótese que se mostrará agora é que Hume tinha uma familiaridade acentuada com as obras maquiavelianas, sendo passível de seguir, às vezes, sua orientação filosófica. E, para situar estas duas posições, é imprescindível apresentar evidência ou boas razões que justifiquem essas proposições, o que se fará doravante.

Em primeiro lugar, não se deve desconsiderar a influência antimaquiaveliana no sécullo XVIII, apesar da quantidade de autores ingleses que recorreram ao seu pensamento para escrever suas próprias obras na Inglaterra. Em segundo lugar, em Tratado da Natureza Humana não há uma única menção ao florentino, tampouco desinências ao vocábulo "Maquiavel". Porém, em um exame mais meticuloso talvez seja possível vislumbrar o que porventura fosse mera coincidência que aparece na seguinte passagem:

Existe uma máxima muito comum em nosso mundo, que poucos políticos querem admitiir, mas que é referendada pela prática de todlas as épocas: que há um sistema de moral concebido especialmente para os príncipes, e muitos mais livre que aquele que deve governar as pessoas privadas. É evidente que não se deve com isso entender que a aplicação dos deveres e das obrigações públicas tenha naquele caso uima menor extensão; ninnguém pode ser tão extravagante a ponto de afirmar que os tratados mais solenes não deveriam ter valor algum entre príncipes (...). O sentido dessa máxima política é, portanto, que, embora a moral dos príncipes tenha a mesma extensão, não tem a mesma força que a das pessoas privadas, podendo ser legitimamente transgredida por um motivo mais fútiti ${ }^{60}$.

Há, de forma perceptível, uma linha comum entre esta passagem e o conteúdo de O Príncipe. Não se deve ignorar este elo, ainda que se hesite em indicar a fonte de inspiração. Afinal de contas, Hume foi um "whig" sob os olhos dos "tories" e, ao mesmo tempo, um "tory" sob os ollhos dos "whigs". É bem provável que Hume tenha escrito o trecho em destaque sob a influência de ponto de vista comum, provavelmente difundido

\footnotetext{
${ }^{56}$ ALTINI, Carlo. "Inghilterra" In: Machiavelli Enciclopedia Machiavelliana, op. cit., p. 23.

57 ibidem, p. 21.

${ }^{58}$ MONTEIRO, Joăo Paulo. Hume e a epistemologia, op. cito, p. 168.

${ }^{59}$ KLIBANSKY, Raymond, MOSSNER, Emest C. New letters of David Hume, op. cit., p. 3.

${ }^{60}$ HUME, David. Tratado da natureza humana: uma tentativa de introduzir o método experimental de raciocínio nos assuntos morais. São Paulo: UNESP, 2001, III, II, XI, 3, p. 607.
} 
em seu tempo. No entanto, este juízo que entende que os príncipes devem manter a segurança do Estado acima de quaisquer pactos estabelecidos, não podendo ser impedidos por febres éticas, advém das leituras maquiavelianas. No fim das contas:

Quando se delibera sobre a salvação da pátiria, não se deve fazer consideração alguma sobre o que é justo ou injusto, piedoso ou cruel, louvável ou ignominioso ao contrário, desprezando-se qualquer medida que lhe salve a vida e mantenha a liberdade $\mathrm{e}^{61}$.

Naquele fragmento de Hume, acerca da "máxima muito comum em nosso mundo", percebe-se ligações com as obras do florentino, porém, quando associado à lição deixada pelos Discorsi do florentino, há, pois, lugar para a interpretação de que o exercício do poder, por parte do príncipe de Maquiavel, que está acima do campo moral quando as circunstâncias assim exigem, de que o escocês aceita a lição de que "a verdade efetiva da coisa"62 é um substrato da história, ensinando que a moral dos príncipes obedece a uma lógica do poder, assim, distinta dos homens comuns, colocando-os acima dos pactos. Afinal de contas, quem bem entende da arte de governar precisa se colocar "no plano baixo para analisar a natureza dos montes e dos lugares altos, e para considerar aquelas coisas de baixo, se põem sobre o alto dos montes"63. Os príncipes devem conhecer os interesses reais de sua nação, tendo, ao mesmo tempo, uma visão mais complexa e mais especifica das questões que podem ou não engrandecer o Estado.

É também por conta destes propósitos que a bibliografia italiana tinha muito a contribuir com a reflexão do fenômeno político de Hume. Não há dúvida que tenha lỉdo a História da Itália, de Francesco Guicciardini, conforme atestam suas menções no Tratado e no ensaio Do refinamento das artes. Dir-se-á, à primeira vista, que Hume compartilhava suas ideias, mormente quando lidavam com a preservação da lei e da ordem, mas também tinham diferenças. Além de estarem ligados entre si, Guicciardini é um leitor de Maquiavel, conforme atestam suas correspondências, como bem indicou Bignotto $^{64}$ ao lembrar que Guicciardini escreveu Considerazioni sui Discorsi del Machiavelli, obra que possui uma posição crítica ao valor da história quanto à perspectiva maquiaveliana, bem como acredita no valor da diplomacia para extinguir as lutas internas, com vista à união dos cristãos $^{65}$. De todo modo, no Tratado, Hume escreve: "numa guerra civil, um partido sempre prefere assumir o risco de apelar para um inimigo estrangeiro a ter de se submeter a seus concidadãos. Guicciardini aplica essa observação às guerras da Itália ${ }^{m 66}$. Na verdade, esta passagem se acentua em Políbios e, ao depois, por leituras próximas, será refletida com mais intensidade no corpus machiavellicus do que em Guicciardini.

A relação entre lutas internas está associada à questão da corrupção e aos efeitos que ela causa no corpo social no decurso do tempo. Guicciardini, no Discorso di Logragno (1998), acredita que o "Consiglio Maggiore" é o caminho para promoção da estabilidade política, desde que se aceite a participação dos Ottimati, homens sábios e experientes, que devido à sua prudência, saberão como resguardar a cidade da corrupção. Maquiavel, por um lado, parte da suposição de que quando a corrupção contamina totalmente o Estado, e não há "virtù" para remediar a vitalidade republicana, a ruína é inevitável. Por outro lado, enquanto instrumento da atividade política, Maquiavel sabe que os homens podem ser seduzidos pela ideia de recompensas e

\footnotetext{
${ }^{61}$ MAQUIAVEL, Nicolau. Discursos sobre a primeira década de Tito Lívio, op. cit., III, 41, p. 443.

${ }^{62}$ Idem. O Príncipe, op. cito, XV, p. 153.

${ }^{63}$ Ibidem, p. 31.

${ }^{64}$ BIGNOTTO, Newton. "Nota metodológica: Guicciardini leitor de Maquiavel". In: Discurso, número 29. São Paulo, 1998, p. 118.

${ }^{65}$ GUICCIARDINI, Francesco. Considerazioni intorno ai Discorsi del Machiavelli: sopra la prima deca di Tito Livio. Edição facsimile da CreatSpace Independent Publis, 2019.

${ }^{66}$ HUME, David. Tratado da natureza humana, op. cit., II, II, VIII, p. 413.
} 
ganhos. Nas duas perspectivas postas, percebe-se que o florentino entende a corrupção como algo adstrito ao exercício político.

A perspectiva de Hume parece ser tão abrangente quanto a de Maquiavel. Este detalhe sugere o conhecimento das obras do florentino acerca da corrupção, compreensão que exige o estudo de vários textos de Maquiavel, "como o Príncipe, a História de Florença e os textos políticos menores" ${ }^{n 67}$, pois nestes escritos se forma um juízo mais apurado da guerra civil, que inexoravelmente é fruto da discórdia e das lutas intestinas, um assunto que parece ser mais latente nos escritos de Maquiavel do que em Guicciardini. Assim, como estratégia de disfarce, de forma oblíqua, parece haver no plano de exposição do raciocínio, a transposição de nomes, dado o conteúdo posto em questão, combinando a proximidade dos florentinos. De modo despercebido, Hume se refere às reflexões de um mencionando outrem, o que não é uma hipótese improvável. Como se disse antes, com uma censura moralizante, a fórmula é beber na grande fonte da discórdia intestina, dando o crédito a Guicciardini, que também era um bom observador da política.

À parte das minhas considerações, David e Mary Norton apontam que o Tratado teve influência do florentino, porque a passagem "os acampamentos são as verdadeiras mães das cidades"68, ${ }^{69}$, para eles, é notadamente uma perspectiva maquiaveliana. $\mathbb{E}$ se, como Norton disse em outro escrito, que "os Ensaios de Hume e seu livro História da Inglaterra constituem, em vários aspectos, continuações de seu primeiro trabalho"70, então, o Maquiavel que aparecerá em outros ensaios de Hume apenas corrobora a ideia de que o Escocês tỉnha uma familiaridade com as obras maquiavelianas, desde o início de sua produção, já que nos ensaios Hume menciona Maquiavel.

É certo que, lidos os ensaios de Hume, vê-se uma passagem reveladora acerca dessa ligação entre os filósofos em lide:

É por isso que é difícil transferir a comédia de uma nação para outra. A uim FRANCESS ou a um INGLÊES não agradam a ANDRIA de TERÊNCIO, ou a CLÍTIA de MAQUIAVEL, em que a bela senhora em torno da qual gira toda a peça não aparece uma vez sequer aos espectadores, ficando sempre oculta nos bastidores, em conformidade com o temperamento reservado dos antigos GREGOS e dos ITALIANOS. Um homem culto e inteligente é capaz de aceitar essas peculiaridades de costumes, mas uma plateia normal jamais será capaz de se despir de suas ideias e sentimentos habituais, a ponto de se satisfazer com cenas que de maneira alguma the são familiares ${ }^{71}$.

Guy Boquet descobriu que "Maquiavel exerceu profunda influência sobre poetas e dramaturgos ingleses"72, no entanto, sendo o florentino de uma cultura e o escocês de outra, era necessário um preparo intelectual para uma devida fruição estética da peça. Talvez por isso este "homem culto e inteligente" " "capaz de aceitar essas peculiaridades de costumes"74 seja o próprio Hume falando de si.

A questão da interpretação literária é, na esteira da influência, outro traço que estabelece o índice expressivo de que Hume era não somente leitor de obras maquiavelianas, mas um bom crítico literário do florentino. A peça trata das paixões

${ }^{67}$ MARTINS, José Antônio. Os fundamentos da república e sua corrupção nos Discursos de Maquiavel. 2007. Tese (Doutorado em Filosofia), Faculdade de Filosofia, Letras e Ciências Humanas, Universidade de São Paulo, p. 30 .

${ }_{68}$ HUME apud NORTON, 2011, p. 928. NORTON, David Fate. "Editors" Annotations" In: A Treatise of human nature Vol. 2. Edited by David Fate Norton and Mary J. Norton. Oxford: Clarendon Press, 2011.

${ }^{69}$ Publicado pela Clarendon Press - nota anterior - , em dois volumes. Na edição brasileira do Tratado, no livro III, parte II, seção VIII, 2001, p. 580, a tradução optou pelo vocábulo "pai" das cidades".

${ }_{70}$ NORTON, David Fate. "A introduction to Hume's thought". In: Hume. Cambridge: Cambridge University Press, 2005, p. 21.

${ }^{71}$ HUME, David. Ensaios morais, politicos e literários, op. cit., p. 391-392, (negritos nossos).

${ }^{72}$ BOQUET, Guy. Teatro e sociedades: Shakespeare São Paulo: Perspectiva, 2012, p. 21.

${ }^{73}$ HUME, David. Ensaios morais, politicos eliterários, op. ciț, p. 392.

${ }^{74}$ Ibidem, p. 392. 
humanas, como elas são espertas e, por conta disso, fonte de conflitos. Neste sentido, um recurso para sua satisfação é a fraude, principalmente porque o que se deseja não

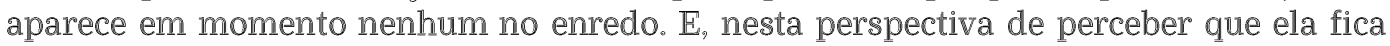
"sempre oculta nos bastidores", sendo a chave-mestra para compreensão da própria encenação teatral, Hume vê que o propósito principal da peça não é a mulher, mas sim as estratégias que os protagonistas recorrem para conquista de sua satisfação, ainda que o instrumento seja a fraude, a mentira e o conluio contra o outro, até mesmo contra o aliado que engana e se percebe enganado e enganando. Esse era o íntimo da história imaginada em Clizia ${ }^{75}$, mas muitos, segundo Hume, por não a entenderem a censurarão. É sobre esta fruição que discorre Hume, que, de resto, mostra sua crítica literária e um conhecimento singular das obras de Maquiavel.

Depois de exposto o quadro da peça, é possível resgatar o que Norton havia posto sobre os escritos posteriores de Hume, de serem sequências de seu primeiro trabalho, porque parece que Hume tinha tomado o florentino como referencial há tempos, o que permitiria compreender bem a coerência estética e a motivação política da peça.

A resposta humeana acerca de sua aproximação com Maquiavel ficará clara em certas passagens, na qual ele escreve sua perspectiva política com uma relação específica a Maquiavel:

1) "Embora haja razões para suspeitar de que o secretário FLORENTINO, que parece ter conhecido melhor os autores ROMANOS que os GREGOS, se tenha equivocado nesse ponto" ${ }^{\text {"T }} 6$

2) "MAQUIAVEL era certamente um grande gênio"7\%;

3) "O próprio MAQUIAVEL demonstra um autêntico sentimento de virtude em sua história de FLORENÇA" ${ }^{\cdots 8}$.

Hume, por sua vez, confirma, nestes trechos, a presença de Maquiavel em suas reflexões, bem como em conjunto de frases relativas à perspectiva do realismo político que poderiam ser arroladas para corroborar este juízo, como as seguintes:

4) "Os escritores políticos estabeleceram como uma máxima que, ao se innstituir qualquer sistema de governo, e ao se fixarem os diversos mecanismos de freios e controles da constituição, todo homem deve ser considerado uim velhaco"79,

5) "dos dois lados há fanáticos sufícientes, que inflamam as paixões de seus partidários e, a pretexto de defenderem o bem público, só visam aos interesses e objetivos da facção a que pertencem" ${ }^{980}$;

6) "A humanidade é tão semelhante, em todas as épocas e lugares, que, sob esse aspecto, a história nada tem de novo ou estranho a nos oferecer. Seu principal uso é apenas revelar os princípios constantes e universais da natureza humana, mostrando os homens nas mais variadas circunstâncias e situações, e provendonos os materiais a partir dos quais podemos ordenar nossas observações e familiarizar-nos com os móveis normais da ação e do comportamento humano" ${ }^{n 1}$.

As passagens têm, assim, uma perspectiva que confere uma visão maquiaveliana do fenômeno político, posto que, na primeira se observa que o legislador, na opinião de

\footnotetext{
${ }^{75}$ MACHIAVELLI, Niccolò. Clizia. Firenze: Einaudi, 1971.

${ }^{76}$ HUME, David. Ensaios morais, políticos eliterários, op. cit., p. 117.

${ }^{77}$ Idem, p. 195.

${ }^{78}$ Ibidem, p. 786.

${ }^{79}$ Tbidem p. 141.

${ }^{80}$ Ibidem, p. 122.

${ }^{81}$ HUME, David. Uma investigação sobre os princípios da moral. Campinas: Unicamp, 1999, p. 113
} 
Hume, deve esperar atitudes egoístas dos homens, jamais dando proeminência à razão no ato de legislar. Na segunda, o filósofo escocês partillha da convicção de que as inclinações políticas dos correligionários têm como base de sula ação alguma paixão (entusiasmo ou superstição) particular do indivíduo, deixando nas entrelinhas que a prudência fica aquém de sua possibilidade de entender o aspecto político como uma situação complexa. Na terceira, Hume concorda com a ideia de imutabilidade da natureza humana logo no início, depois segue a interpretação florentina de que os fatos são corroborados pela história; que funciona como um laboratório para conceber planos políticos com base na conduta regular dos homens. Desta perspectiva, percebe-se que Hume se filia à corrente do realismo político de Maquiavel, além de entender que os conflitos são naturais à espécie, mas que a política tem como função o ordenamento da cidade, comungando com a perspectiva do realismo político e das razões de Estado.

Não há dúvidas de que Hume conhecia as obras maquiavelianas, pois se esses fragmentos fornecem um indício desta ligação, a carta de Hume enviada para Horace Walpole é quase uma confissão, já que ele escreve:

Fuil seduzido, por exemplo, por todos os melhores historiadores, mesmo entire os modernos, tais como Maquiavel, Frapaolo, Davila, Bentivoglio; sem considerar que aquela prática fosse mais moderna que sua época, e por ter sido uma vez apresentada, deveria ser seguida por cada escritor. $\mathbb{E}$, é fácil para o historiador mais falso e mais parcial carregar sua margem com citações, nem há outro método para garantir a fidelidade de um autor do que ler a maioria dos escritores originais de qualquer período; no entanto, o leitor tem motivos para esperar que os fatos mais relevantes, pelo menos, todos, de qualquer maneira nova, sejam apoiados pelas autorias competentes ${ }^{82}$.

A essa altura, imagina-se que a presença maquiaveliana nos escritos de Hume já esteja perfeitamente expressada nestas linhas, já que, em termos de fragmentos e de passagens típicas da perspectiva do florentino, avolumam-se corroborações. No entanto, para contribuir com este quadro, é preciso mostrar que o escocês tinha tomado Maquiavel para consulta também em sua História da Inglaterra, quando aí faz uma análise acerca da obediência dos soldados ingleses, espanhóis e franceses aos seus respectivos monarcas. Todavia, o mais significativo é o que Hume escreve: "Maquiavel, em Discursos sobre a Primeira Década de Títo Lívio, diz repetidas vezes, que a França era uma monarquia cada vez mais popular na Europa"83. Esta referência direta aos Discorsi do Florentino, mostra que Hume usa as obras de Maquiavel em suas reflexões, como mostra que ele "says repeatedly", conforme escreve neste trecho. Para além desse objetivo, percebe-se que, ao recorrer ao florentino na História da Inglaterra e nos Ensaios, com menções diretas a Maquiavel, ele corrobora a evidência, com o próprio punho do Escocês, de que ele havia lido suas obras, principalmente por lidar com temáticas enfrentadas pelo Florentino.

Hume evocava o florentino em seus escritos, o que parece corroborar a ideia inicial de Norton de que as obras maquiavelianas foram lidas por Hume, como fazia parte referencial de suas próprias ideias, o que podia ser natural, uma vez que Maquiavel teve uma importância fundamental na história da Inglaterra. Aliás, sendo Hume também um historiador, não tinha como não se imiscuir na contribuição deixada pelo florentino, que foi capaz de instrumentalizar uma série de autores, inspirando-os em obras próprias. A esse propósito de fornecer as bases para análises políticas, referindo-se aos comentadores contemporâneos de Hume, especificamente a Frederick Whelan, que procurou entender a situação política de Hume depois de uma minuciosa investigação acerca de suas influências, parece acreditar que o escocês colheu os pressupostos de sua

${ }^{82}$ Greig, J.Y.T. The letters of David Hume. Oxford: At the Clarendon Press, 1932, p. 284.

${ }^{83}$ HUME, David. The History of England: from the Invasion of Julius Caesar to The Revolution in $1688.6 \mathrm{v}$. Indianapolis: Liberty Fund, 1983, vol. V, p. 563. 
reflexão política no patrimônio filosófico produzido pelo florentino, motivo pelo qual ele afirma que

\begin{abstract}
Hưme abraça vários pressupostos importantes e compromissos normativos quie seriam incluídos na maioria dos relatos do liberalismo clássico, a saber: (1) individualismo auto-interessado como princípio metodológico e, num grau substancial, como suposição sobre a motivação real em termos sociais e da vida política; (2) uma visão da política como atividade centrada na tentativa de promover interesses diversos e estratégias para conter ou gerenciar conflitos e não como busca da harmonia social ou da perfeição humana; (3) tolerância e abertura religiosa e intelectual; (4) entusiasmo pelo crescimento econômico através dos direitos de propriedade, do comércio, da concorrência e dos mercados livres; e (5) uma elevada valorização da liberdade pessoal, restringida pelo respeito de una liberdade semelhante em outros e entendida principalmente como o produto da lei e do governo constitucional limitado $0^{84}$.
\end{abstract}

Decididamente, para Whelan, Hume havia tomado Maquiavel como referência para sua interlocução filosófica, motivo pelo qual se sente o reflexo do florentino nos escritos do escocês, compartilhando uma visão comum em várias perspectivas. Assim, além dos temas elencados acima, é preciso adicionar outros que os reconduzam ao realismo político, que entende a vida política como um conflito interminável, já que o auitointeresse é o móvel das ações humanas, tendo por trás o jogo das paixões humanas, sempre espertas; bem como, a proeminência da experiência na análise dos fenômenos políticos; e, finalmente, o estudo da história como laboratório de análise do fenômeno político. Essas singularidades levam Whelan a afirmar que

Hume era uim leitor atento de Maquiavel e refere-se a ele, normalmente de forma favorável, em muitas ocasiões. Além de referências explícitas, há inúmeras passagens e temas nas obras políticas e históricas de Hume que derivaram de Maquiavel ou que são uma reminiscência impressionante de temas sobre a teoria políticica de Maquiavel ${ }^{85}$.

Outros autores, dentre eles John W. Danford ${ }^{86}$, Philippe Saltel ${ }^{87}$ e Giuseppe Cospito ${ }^{88}$, cada qual com suas especificidades, traçam uma série de relações entre o florentino e o escocês, que merecem ser consideradas pelos que procuram as fontes nas quais os grandes filósofos foram buscar os pressupostos de suas reflexões.

\title{
PARTE III - Conclusão
}

A bem da verdade, resta evidente que David Hume tinha familiaridade com obras maquiavelianas, como O Príncipe, os Discorsi, História de Florença, Clizia e, também, Uma investigação sobre os princípios da moral ${ }^{89}$. Não se trata de mera hipótese, pois, além das menções em seus escritos, sua correspondência pessoal serve como um indício fundamental desta relação, uma vez que abandonada todas as implicações filosóficas, e desde que se tem em conta à presença da obra do florentino nos escritos de Hume pode se ler o seguinte trecho:

${ }^{84}$ WHELAN, Frederick. Hume and Machiavelli political realism and liberal thought. Maryland: Lexington Books, 2004, p. 3.

${ }^{85}$ Idem, p. 2-3.

${ }^{86}$ DANFORD, John W. "Getting our bearings: Machiavelli and Hume". In: Machiavelli's liberal republican legacy. Cambridge: Cambridge University Press, 2010.

${ }^{87}$ SALTEL, Philippe. "Machiavel Himself...": Hume et le "Secrétaire de Florence". In Revue philosophique de la France et de l'étranger, no 1, tome 133, 2008.

${ }^{88}$ COSPITO, Giuseppe. "Machiavelli e Hume: Tra scrittoio e tavalo da giocco". In: I castelli di Yale online. Anno II, numero 1, 2014

${ }^{89}$ Ali, Hume cita literalmente Maquiavel, mas tal referência mostra que ele tem uma familiaridade com os Discorsi. HUME, David. Uma investigação sobre os princípios da moral. Campinas: Unicamp, 1995, p. 108. 
há uma passagem muita boa para seu propósito em Maquiavel que tinha recaído sobre isso. Ele diz que Flanders é muito fria, uma Terra que não produzirá Milho, e que é dependente da França para seu Pão. İsto prova quão ignorante um italiano pode $\operatorname{ser}^{90}$

A passagem acima mostra que Hume tinha um conhecimento inusitado das obras de Maquiavel, (pois, somente assim, poderia fazer este tipo de comentário), sabendo de detalhes que vão além do corpus politicum do florentino. Ademais, não restam dúvidas, depois das descobertas de Orsini e de Whitfiel que os escritos de Maquiavel circundavam há tempos na Inglaterra, influenciando autores como Hume, que além de filósofo era também um historiador e, portanto, não podia ignorar as produções políticas de Maquiavel já que havia se imiscuído em suas produções literárias, como foi o caso de Clizia, na qual "a bela senhora (...) não aparece uma vez sequer aos espectadores ${ }^{\prime \prime 1}$. Não se deve excluir o fato de que louvar o florentino era altamente perigoso em um cenário em que a política e a religião se misturavam quando da análise dos escritos de Hume. Nesse ambiente politizado, entre os defensores das prerrogativas do rei e do parlamento, os leitores de Maquiavel (e o próprio Hume) costumavam usar uma série de estratégias para colocar suas posições, inclusive o uso do silêncio, ou, por modos oblíquos para não serem considerados admiradores de um homem que, aos olhos de Reginald Pole, teria emprestado um dedo a Satanás, para este escrever O Príncipe.

Conforme foi mostrado, as obras de Maquiavel estavam à disposição da elite inglesa há tempos; e elas foram lidas de modo variado, posto que havia uum esforço intelectual desta alta sociedade para compreender a língua italiana. Acontece, entretanto, que o tempo trouxe mudanças políticas e os escritos do florentino ajudaram uns a tomar consciência clara do quadro político inglês, ainda que os outros, principalmente o público, leigo, manifestassem um enorme desprezo pelas obras do florentino. Na prática, Maquiavel era lido por muitos, sendo a inspiração para autores que promoviam as polêmicas ideológicas entre defensores das prerrogativas reais versus parlamentares.

Na Inglaterra de Hume, não estava em curso uma simples disputa ideológica entre whigs e tories, mas sim uma luta pelo domínio econômico através do controle político. Este e aquele partido se sustentavam em princípios que favoreciam ao crescente facciosismo do governo e, por decorrência, ameaçavam à estabilidade do governo e a ordenação social. Hume desejava abrir os olhos de seus contemporâneos para este modo pernicioso de lidar com a política, pondo-se como um crítico destas matrizes (princípios do entusiasmo e da superstição) ao mesmo tempo em que expõe sua análise por outras perspectivas que se aproximam daquelas postas por Maquiavel.

A bem da verdade, não se pode mensurar o grau de influência que Maquiavel tinha sobre Hume quando este estava escrevendo, já que a essa altura há elementos comprovados de que o escocês conhecia os escritos do florentino. $\mathbb{E}$ há boas razões, devido ao número de menções diretas e indiretas, para acreditar que Hume era um leitor muito interessado nas obras de Maquiavel, não se contendo apenas com o Príncipe e os Discorsi.

\section{Referências}

ALTINI, Carlo. "Inghilterra" In: Machiavelli. Enciclopedia Machiavelliana (a cura di Gennaro Sasso). Roma: Treccani, v. II, pp. 18-23, 2014.

ARIENZO, Alessandro. "From Machiavellian Policy to Parliamentary reason of state: sketches in early Stuart political culture In Machiavellian Encounters" In: Tudor and

${ }^{90}$ KLIBANSKY, Raymond, MOSSNER, Emest C. New letters of David Hume, op. cit., p. 32.

${ }^{91}$ HUME, David. Ensaios morais, políticos eliterários, op. cit., p. 391-392. 
Stuart England. Literary and Political influences from the Reformation to the Restoration. Farnham: Ashgate, 2013.

BARON, Hans. En busca del humanismo cívico florentino: ensayos sobre el cambio del pensamiento medieval al moderno. México: Fondo de Cultura Económica, 1993.

BIGNOTTO, Newton. "Nota metodológica: Guicciardini leitor de Maquiavel". In: Discurso número 29. São Paulo, 1998, 111-131.

BOBBIO, Norberto. Teoria geral da política: a filosofia política e as lições dos clássicos. Rio de Janeiro: Elsevier, 2000.

BONGII, S. "Un aneddoto di bibliografia Machiavellesca". In: Archivo Storico Italiano, 5a Serie - XIX. Firenzi: G.P. Vieusseux, 1897.

BOQUET, Guy. Teatro e sociedades: Shakespeare. São Paulo: Perspectiva, 2012.

CILIBERTO, Michele. "Machiavelli e Il Principe nell'Inghilterra tra il XVI e il XVII secolo". In: Il Principe di Niccolò Machiavelli e il suo tempo: 1513 - 2013. Roma: Treccani, 2013.

COLI, Daniela. Hobbes, Roma e Machiavelli nell'Tnghilterra degli Stuarts. Firenze: Casa Editrice le Lettere, 2009.

COSPITO, Giuseppe. "Machaivelli e Hume: Tra scrittoio e tavalo da giocco". In: I castelli di Yale online. Anno II, numero 1, 2014.

DA GAMBA BASSANO, Bartolomeo. Serie dei testi di lingua. $E$ di altre opere importanti nella italiana letteratura scritte dal secolo XIV al XIX. Venezia: Arnaldo Forni, MDCCC XXXIX.

DANFORD, John W. "Getting our bearings: Machiavelli and Hume". In: Machiavelli's liberal republican legacy. Cambridge: Cambridge University Press, 2010.

FIRPO, Massimo. "Il volto, la Maschera, la caricatura. Sulla celebre 'testina' di Niccolò Machiavelli". In: Rivista dell'Istituto Nazionale de Studi sul Rinascimento. LII, 2012.

FRAIESE, Vittorio. "Index librorum prohibitorum". In: Machiavelli. Enciclopedia Machiavelliana (a cura di Gennaro Sasso). Roma: Treccani, v. II, pp. 12-17, 2014.

FRAJESE, Vittorio. Nascita dell'Indice. La censura ecclesiastica dal Rinascimento ala Controriforma. Editrice Morcelliana: Brescia, 2008.

GERBER, A. "All of five fictitious Italian Editions of writings of Machiavelli and three of those of Pietro Aretino printed by John Wolfe of London (1584-1589)". II In: Modern Language Notes, Vol. 22, ㄲo 5 (May, 1907).

Greig, J.Y.T. The letters of David Hume. Oxford: At the Clarendon Press, 1932.

GUICCIARDINI, Francesco. Considerazioni intomo ai Discorsi del Machiavelli: sopra la prima deca di Tito Livio. Edição facsimile da CreatSpace Independent Publis, 2019.

HUME, David. Ensaios morais, políticos e literários. Rio de Janeiro: Topbooks, 2004.

HUME, David. Uma investigação sobre os princípios da moral. Campinas: Unicamp, 1999.

HUME, David. The History of England from the Invasion of Julius Caesar to The Revolution in 1688. 6 v. Indianapolis: Liberty Fund, 1983.

HUME, David. Tratado da natureza humana: uma tentativa de introduzir o método experimental de raciocínio nos assuntos morais. São Paulo: UNESP, 2001.

KLIBANSKY, Raymond, MOSSNER, Emest C. New letters of David Hume. Oxford: At the Clarendon Press, 1969. 
LEFORT, Claud. Maquiavelo: Lecturas de lo político. Fernández: Trotta, 2010.

MACHIAVELLI, Niccolò. Clizia. Firenze: Einaudi, 1971.

MAQUIAVEL, Nicolau. Discursos sobre a primeira década de Tito Lívio. São Paulo: Martins Fontes, 2007b.

MACHIAVELLI, Niccolò. The Prince. London: Long Acre, 1905.

MAQUIAVEL, Nicolau. O Príncipe. Edição bilíngue. São Paulo: Hedra, 2007a.

MARTINS, José Antônio. Os fundamentos da república e sua corrupção nos Discursos de Maquiavel. 2007. Tese (Doutorado em Filosofia), Faculdade de Filosofia, Letras e Ciências Humanas, Universidade de São Paulo.

MEYER, Edward. Machiavelli and the Elizabethan Drama. Wiemar: Verlog Von Emil Felber, 1897. Edição facsimile da Kessinger Publishing, 2007.

MONTEIRO, João Paulo. Hume e a epistemologia. Vila da Maia: Imprensa Nacional/Casa da Moeda, 1984

MORTON, A.L. A história do povo inglês. Rio de Janeiro: Civilização Brasileira, 1970.

NORTON, David Fate. "A introduction to Hume's thought". In: Hume. Cambridge: Cambridge University Press, 2005.

NORTON, David Fate. "Editors" Annotations" In: A Treatise of human nature. Vol. 2. Edited by David Fate Norton and Mary J. Norton. Oxford: Clarendon Press, 2011.

ORSINI, Napoleone. "Elizabethan manuscript translation of Machiavelli's Prince". In: Journal of the Warburg Institute, vol. 1, № 2 (Oct. 1937a).

ORSINI, Napoleone. Studii sul Rinascimento Italiano in Inghilterra. Con alcuni testi inglesi inediti. Firenzi: G. C. Sansoni, $1937 \mathrm{~b}$.

POCOCK, J.G.A. The machiavellian moment Florentine political thought and the Atlantic Republican tradition. New Jersey: Princeton, 2003.

POLE, Cardenal. "Apología Ad Carolum Quintum Caesarem". In: El Cardenal Pole de la política como virtud en tiempos de El Príncipe. Madrid: Unión Editorial, 2013.

POLE, Cardenal. Defense of the Unity of the Church. Westminster, Mariland: The Newman, 1965.

PRAZ, Mario. Machiavelli in Inghilterra ed altri saggi. Firenzi: Tumminelli, 1943.

PRAZ, Mario. "The flaming heart: essays on Crashaw, Machiavelli, and other studies". In: the relations between Italian and English literature from Chaucer to T.S. Eliot by Mario Praz. New York: The Norton, 1973.

PUIGDOMENECH, Helena. Maquiavelo en España Madrid: Fundación Universitaria Española, 1988.

RAAB, Felix. The English Face of Machiavelli. A changing interpretation $1500-1700$. London: Routledge, 2013.

SALTEL, Philippe. "Machiavel Himself...": Hume et le "Secrétaire de Florence". In Revue philosophique de la France et de l'étranger, no 1 , tome 133, 2008, p. 31-42.

TARANTINO, Maurizio. "Testina" In: Machiavelli. Enciclopedia Machiavelliana (a cura di Gennaro Sasso). Roma: Treccani, v. II, pp. 609-610, 2014.

WEBER, Max. A política como vocação. São Paulo: Cultrix, 2004.

WHELAN, Frederick. Hume and Machiavelli political realism and liberal thought. Maryland: Lexington Books, 2004. 
WHITFIELD, J.H. The Charlecote Manuscript of Machiavelli's "Prince". (Reprinted from Italian Studies, Vol. XXII, 1967).

YATES, Frances A. "Italian Teachers in Elizabeth England". In: Journal of the Warburg Institute, V. 1, no 2 (Octo, 1937).

Doutor em Educação (PUC-SP, 2010)

Pós-Doutorado em Filosofía (PUCSP)

Professor Titular (Pleno) de Filosofia da Universidade Estadual de Feira de Santana (UEFS)

Email: nilloreis@uefs.br 